\title{
TEM Study for the Identification of Phases in Al2024 Alloys Cold Rolled-30\%\&
}

J.C Guía-Tello ${ }^{1}$, C.G. Garay-Reyes ${ }^{1}$, H. M. Medrano-Prieto ${ }^{2}$, G. Rodríguez-Cabriales ${ }^{1}$, M.A. Ruiz-EsparzaRodriguez ${ }^{1}$, J.M. Mendoza-Duarte ${ }^{3}$ and R. Martínez-Sánchez ${ }^{4}$

${ }^{1}$ Centro de Investigación en Materiales Avanzados (CIMAV), Laboratorio Nacional de Nanotecnología, Miguel de Cervantes No. 120, CP 31136, Chihuahua, Chih., México., Chihuahua, Chihuahua, Mexico, ${ }^{2}$ Universidad Tecnológica de Chihuahua Sur. Km. 3 Carretera Chihuahua-Aldama S/N, CP 31313, Chihuahua, Chih., México., Chihuahua, Chihuahua, Mexico, ${ }^{3}$ Centro de Investigación en Materiales Avanzados (CIMAV), Laboratorio Nacional de Nanotecnología, Miguel de Cervantes No. 120, CP 31136, Chihuahua, Chih., México., United States, ${ }^{4}$ Centro de Investigación en Materiales Avanzados (CIMAV) Laboratorio Nacional de Nanotecnología, Miguel de Cervantes No. 120, CP 31136, Chihuahua, Chih., México., Chihuahua, Chihuahua, Mexico

The Al-Cu-Mg system most used in the aeronautic industry corresponds to the 2024 aluminum series [1]. The strengthening mechanism more employed for these alloys consists in the precipitation hardening due to the precipitates formed can be crystallographically coherent with the aluminum matrix, and their fine dispersion enhances the alloy's mechanical properties [2]. The Al-Cu-Mg system's high strength due to plastic deformation before artificial aging has been reported [3, 4]. However, an in-depth study on the identification of phases has not been carried out. Thus, a plastic deformation process by cold-rolled after solution treatment was performed to identify different types precipitated in the alloy.

Commercial A12024 alloy was used as raw material and subjected to fusion, hot extrusion, and solution heat treatment (SHT). Degassing of molten Al2024 alloy was carried out with argon gas (20 psi) for 15 min, followed by the addition of $0.62 \mathrm{~g}$ of Al-5Ti-1B as a grain refiner. The SHT was performed in an electric furnace at $495^{\circ} \mathrm{C}$ for $7 \mathrm{~h}$; subsequently, the samples were quenched in water at $60{ }^{\circ} \mathrm{C}$. Further, the alloy was deformed by cold working-30\% $\%$. Aging heat treatments (AHT) for all deformed samples were performed in a FelisaTM furnace. The conditions of AHT used were $195^{\circ} \mathrm{C}$ for 30, 60, 300, 600, 3000, and $6000 \mathrm{~min}$, followed by quenching in the water at room temperature. Later, selected samples were prepared by Focused Ion Beam (FIB) operated at 5-30 kV (step $5 \mathrm{kV}$ ) and were analyzed in TEM mode using a transmission electron microscope JEM 2200 FS + CS operated at $200 \mathrm{kV}$ and equipped with a spherical aberration corrector. Samples analyzed by TEM were oriented near axes zone 001 and structural simulation of results was performed.

Figure 1 shows BF-TEM and NBD analysis of samples cold rolled 30\% $\varepsilon$ and aged to different times. At initial condition (Figure 1 (a, a1)), some diffraction spots identified suggest that $\mathrm{Al} 2 \mathrm{Cu}$ phase, $\mathrm{Cu}$, and $\mathrm{Mg}$ are present in the alloy. However, at 30 min aging, different structures coexist in the aluminum matrix: GPB-II, $\theta$ '"-Al3Cu, and $\theta^{\prime}-\mathrm{Al} 2 \mathrm{Cu}($ Figure $1(\mathrm{~b}, \mathrm{~b} 1))$. The simulation carried out indicated that results are consistent with diffraction spots pattern located 1/3 and 2/3 \{220\} Al and \{200\} Al parallel to [100] axis aluminum matrix [5]. In addition, forbidden reflections located between $1 / 2\{220\} \mathrm{Al}$ and $\{200\} \mathrm{Al}$ are attributed to $\theta^{\prime}[6]$. Faint streaks parallel to [010] matrix direction corresponds to one variant of phase $S^{\prime}$, viewed along each of 001 directions where the streaks are oriented with their long [100]S axis parallel to the $001[6,7]$. At 300 min aging, the NBD diffraction pattern confirms the precipitation of the $S^{\prime}$ phase (Figure $1(\mathrm{c}, \mathrm{c} 1)$ ), where strong reflections around the forbidden $\{110\} \mathrm{Al}$ are primary reflections of the planes $\{112\}$ and $\{131\}$ [8]. Additionally, the NBD also showed faint streaks of some S phase variants that give rise to the mentioned pattern [6, 7]. Further, at 600 min aging time, the diffraction pattern only showed reflections of the S' phase, and reflections of variants were not observed (Figure $1(\mathrm{~d}, \mathrm{~d} 1)$ ). The above could indicate that the cold-rolled $30 \% \varepsilon$ originates that the precipitation of S' phase in A12024 alloy, which begins at 300 min aging due to the formation of different variants, but stable 
S' phase is obtained at 600 min aging. A summary of the different phases with their lattice parameters to different aging times is showed in Table $\mathrm{I}$.
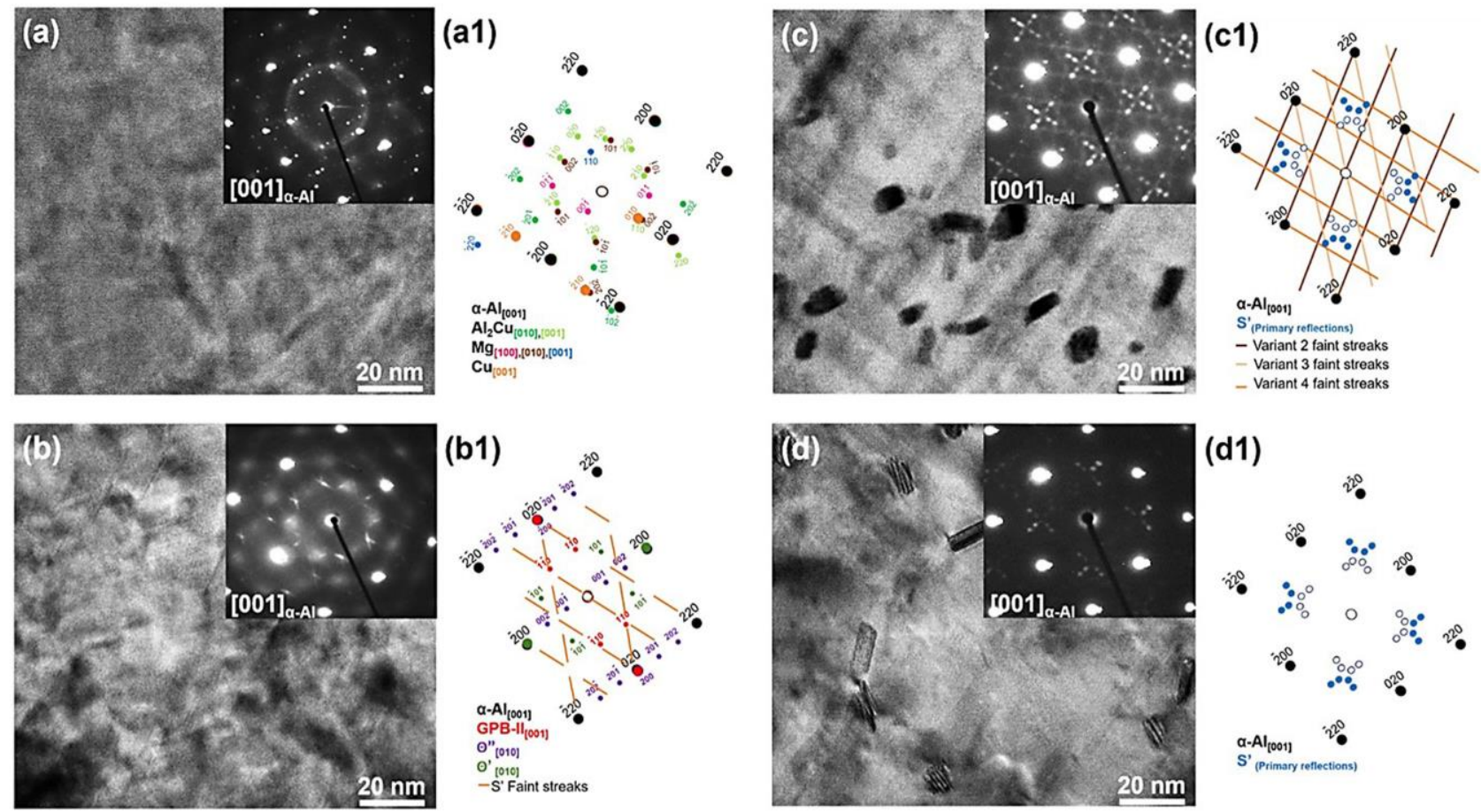

Figure 1. Figure 1. TEM studies of 2024 aluminum alloy cold rolled $30 \% \varepsilon$ aged at $195^{\circ} \mathrm{C}$ and structural simulations to different aging time: (a, a1) 0 min; (b, b1) $30 \mathrm{~min}$; (c, c1) $300 \mathrm{~min}$; (d, d1) $600 \mathrm{~min}$.

\begin{tabular}{|c|c|c|c|c|c|}
\hline \multirow[t]{2}{*}{ Aging time (min) } & \multirow[t]{2}{*}{ Phase } & \multirow[t]{2}{*}{ Space group } & \multicolumn{3}{|c|}{ Lattice parameters $(\AA)$} \\
\hline & & & $\mathbf{a}$ & b & $\mathbf{c}$ \\
\hline & $\mathrm{Cu}$ & Fm-3m & 3.6 & 3.6 & 3.6 \\
\hline \multirow[t]{3}{*}{0} & $\mathrm{Mg}$ & $\mathrm{P} 63 / \mathrm{mm}$ & 3.203 & 3.203 & 5.2002 \\
\hline & $\mathrm{Al}_{2} \mathrm{Cu}$ & $\mathrm{I} 4 / \mathrm{mcm}$ & 4.928 & 4.928 & 4.928 \\
\hline & GPB-II & $\mathrm{Cmmm}$ & 12 & 4 & 4 \\
\hline \multirow[t]{3}{*}{30} & $\theta$ ' $-\mathrm{Al}_{3} \mathrm{Cu}$ & $\mathrm{P} 4 / \mathrm{mbm}$ & 4.06 & 4.06 & 7.80 \\
\hline & $\theta^{\prime}-\mathrm{Al}_{2} \mathrm{Cu}$ & $\mathrm{I}-4 \mathrm{~m} 2$ & 4.04 & 4.04 & 5.8 \\
\hline & $\mathrm{S}^{\prime}$ & $\mathrm{Cmcm}$ & 4.03 & 9.3 & 7.08 \\
\hline 300 & $S^{\prime}$ variants $(2,3,4)$ & --- & --- & ---- & --- \\
\hline 600 & $S^{\prime}$ & $\mathrm{Cmcm}$ & 4.03 & 9.3 & 7.08 \\
\hline
\end{tabular}

Figure 2. Table I. Identification of phases in Al2024 alloy to different aging times. 


\section{References}

[1] J.Z. Liu, S.S. Yang, S.B. Wang, J.H. Chen, C.L. Wu, J. Alloys Compd. 613 (2014) 139-142.

[2] S.Q. Wang, M. Schneider, H.Q. Ye, G. Gottstein, Scripta Mater. 51 (2004) 665-669.

[3] G.B. Winkelman, K. Raviprasad, B.C. Muddle, Acta Mater. 55 (2007) 3213-3228.

[4] N. Ünlu, B.M. Gable, G.J. Shiflet, E.A. Starke Jr., Metall. Mater. Trans. A 34A (2003) 2757-2769.

[5] A. Wiengmoon, J. T. H. Pearce, T. Chairuangsri, S. Isoda, H. Kurata, H. Saito, Micron 45 (2013) 3236.

[6] S.C. Wang, M.J. Starink, Int. Mater. Rev. 50 (2005) 193-215.

[7] S. P. Ringer, S. K. Caraher, I. J. Polmear, Scripta Mater. 39:11 (1998) 1559-1567.

[8] A. K. Gupta, P. Gaunt, M. C. Chaturvedi, Philos. Mag. A 55:3 (1987) 375-387 